\title{
Resilience beyond Formal Structures: A Network Perspective towards the Challenges of an Aging Workforce in the Oil and Gas Industry
}

\author{
Fabio Bento ${ }^{1, *(\mathbb{D})}$ and Luciano Garotti ${ }^{2}$ \\ 1 Department of Behaviorial Science, OsloMet-Oslo Metropolitan University, 0130 Oslo, Norway \\ 2 Petrobras Research and Development Center-Cenpes, Rio de Janeiro 21941-970, Brazil; \\ luciano.garotti@petrobras.com.br
}

Received: 8 February 2019; Accepted: 4 March 2019; Published: 6 March 2019

check for updates

\begin{abstract}
Changes in workplace demographics in the oil and gas industry have raised a concern about the risks of a knowledge-loss crisis due to mass retirement. The industry response has often consisted of strategies aimed at mapping knowledge across organizational units, codifying knowledge in databases, and mentoring new staff. However, such common managerial responses show important limitations in terms of grasping tacit and network-based dimensions of knowledge in complex oil production operations. Therefore, there is an industrial need for innovative knowledge management practices. In this conceptual article, we look at the knowledge-loss crisis from the perspective of network resilience in complex systems. A central assumption here is that it is important to look at retiring staff not only in terms of their explicit knowledge, but also in relation to their roles in evolving networks of interactions. Why do some social systems adapt to the departure of some individuals, recover from eventual knowledge-loss crises, and keep performing its functions? From an anticipatory logic, network analysis may show the initial conditions of a system and identify possible loss scenarios. From an adaptive logic, network analysis may inform interventions aimed at facilitating processes of interactions from which new knowledge may emerge and spread. Integrated operations may be a step in this direction.
\end{abstract}

Keywords: oil and gas industry; resilience; aging workforce; network analysis; complex adaptive systems

\section{Introduction}

There is a growing concern in the oil and gas industry about changes in workforce demographics [1,2]. The historical development of the industry is intrinsically associated with the employment of members of the baby-boom generation born between 1945 and 1964 and who are now reaching retirement age [3]. Such concern is informed by different reports that estimate that the industry might lose up to $50 \%$ of its workforce within five to ten years [4-6]. From a knowledge management perspective, rapid employee turnover is often addressed with an expressed concern with resource drain in the form of a knowledge-loss crisis [7]. Such concern carries important assumptions regarding knowledge that have embedded knowledge management practices in organizations. Organizational responses to knowledge crises have often consisted of strategies that emphasize knowledge storage and talent retention. The strategies are permeated by three central concerns: systems robustness, positions in formal hierarchical structures, and explicit knowledge. This traditional approach has played and will likely continue to play an important role. However, the main argument that we develop in this article is that organizational responses to the knowledge-loss crisis in the oil and gas industry will have a limited effect unless they incorporate a view on systems resilience and an understanding of processes of interactions beyond formal and rather static organizational hierarchies. 
The focus on systems [8] as units of adaptation [9,10], and networked ongoing processes of communication that transcends formal hierarchical structures [11,12] provides valuable insights. From a complex systems perspective, organizations have the characteristics of evolving patterns of communication. At this stage, it is important to clarify that the main assumption that permeates this article is that there is a complex interplay between formal hierarchical structures and informal structures that we call networks. We do not mean that organizations have to choose between system robustness in formal structures and resilience in informal structures. Such interplay is well recognized by literature of complex studies, evolution [9] and organizational network analysis [13]. As pointed out by Clement and Puranam, [14] (p. 3893), there is a need to understand "the linkages among structures of task interdependence and the networks of social interactions unfolding upon them, guided by the formal structure of organizations". While we usually design organizations, a complex system is related to evolving patterns of interactions that have an emerging structure called a network.

In oil and gas, most organizational responses to the challenges of an aging workforce have assumed the form of knowledge management approaches. In this sense, Parise [15] presents a comprehensive case for the different contributions of social network analysis (SNA) to knowledge management and human resource development in organizations. Organizations implement different strategies for knowledge sharing that range from codification and storage of explicit knowledge to personalization focusing on people-to-people interactions, facilitating tacit knowledge communication and know-how in real life. The two strategies can actually coexist. As claimed by Parise [15], SNA is particularly useful in designing and informing personalization strategies and human resource interventions. SNA can be used to identify causes and possible alternatives to overcome intergroup fragmentation, analyze knowledge sharing among groups and facilitate communication. Furthermore, SNA can help the integration of expertise facilitating the emergence of innovation and creation of knowledge. Open innovation may benefit from understanding the mechanisms of social contagion in networks [16].

In the first part of the article, we review the definition of system robustness and traditional organizational responses to employee turnover. In the second part, we present an alternative perspective permeated by the concept of resilience in complex adaptive systems. In the third, we describe the particularities of oil and gas production making it a rich case to be explored. In the last part, we offer a reflection upon system resilience and argue that network analysis can contribute in two ways: first, in anticipatory logic in which knowledge-loss risks can be identified, and second, by facilitating a network structure that facilitates the spread of complex information and thereby system adaptation.

\section{The Traditional Approach: Mass Retirement from a System Robustness Perspective}

In modern organizations, the most common managerial response to staff retirement consists of looking at the position of employees in formal organizational charts and substituting them with arriving ones with similar background and expertise. In the oil and gas industry, there are also mentoring strategies aimed at tacit knowledge retention, thereby maintaining system stability. As described by Grant [17], knowledge management practices in the oil and gas industry have assumed two forms: applications of informational technology to store and manage explicit knowledge, and face-to-face practices facilitating tacit [18] knowledge transfer. This finding is based upon a longitudinal analysis of knowledge management practices in eleven major companies in the sector. Oil and gas companies have been confronted with the challenges of transferring tacit knowledge deriving from employees' diverse experiences [17]. This was usually done by facilitating interaction between individuals and groups. Some companies have implemented mentoring schemes and group discussion, thus facilitating communication and tacit knowledge transfer from retirees to new staff. However, there are certain limits on the extent to which the company can oblige retirees to disclose tacit knowledge. First, there is the knowledge of tacit knowledge itself which is highly related to experiential knowledge and often difficult to verbalize in explicit ways. This is described by Grant [17] (p. 97) in the following 
terms: "the stock of expertise and knowledge within an organization -located within the brains of employees- that cannot be easily expressed or identified, but may nevertheless be essential to its operation". Second, from a behavioral perspective, implementing sanction mechanisms does not seem to promote a knowledge sharing culture in organizations.

There are at this stage no systematic assessments of the consequences of mass retirement in the oil and gas sector. However, different accounts from practitioners illustrate both knowledge-loss and the limitations of current practices. In one company, departing platform operators were required to fill up a form describing the knowledge necessary to perform work tasks. As practitioners describe, this practice is ineffective in grasping tacit knowledge and does not help new staff to build their own experiential knowledge.

It is thus expected to maintain system stability by managing the position of individuals and replacing leaving staff in static organizational structures and formal hierarchies. The explicit goal of this approach is to maintain system functionality by reducing the impact of the departure of some agents in the systems. In this respect, such an approach resonates with the concept of robustness defined by Barabási [19] (p. 303) in the following terms: "a system is robust if it maintains its basic functions in the presence of internal and external errors. In a network context, robustness refers to the system's ability to carry out its basic functions even when some of its nodes and links may be missing".

Robustness is related to the degree to which a system can maintain its functionality even in the case of incomplete information or absence of some of its components [20]. Robustness is an important and enlightening concept for our understanding of designed systems. However, the study of adaptive systems raises questions beyond maintaining system functionality by focusing on the possibilities for renewal, self-organization, learning, and the exploration of new knowledge. This is particularly important when looking at the impacts of employee turnover, and in the specific case of oil and gas, with the mass retirement of experienced personnel. One may, for instance, inquire how a system will behave in the absence of central agents; individuals that connect different clusters; and/or individuals who may at a first glance seem to have a peripheral position but may play important roles in maintaining contacts with important external links.

We may reflect upon the different implications of employee turnover for organizations. On one hand, we may consider the negative implications of turnover for the reliability of operations [21]. On the other hand, it is important to reflect upon its possible positive consequences for adaptation to environmental changes [22]. This is a helpful conceptual distinction. Nevertheless, the literature about evolution in organizations [9] and complex systems [10] shows that exclusive focus on one at the expense of the other may bring negative effects for the organization. The most common knowledge management approach to mass retirement in oil and gas seems to be embedded by a focus on stability in the form of reliability of work processes. Developing adaptive capacity beyond system robustness is important for oil and gas not only due to the aging and retirement of a large share of its workforce. In this respect, we suggest that there is a space for the coexistence and interplay between the traditional management approach with a focus on system robustness (reliability) and strategies looking at developing systems resilience (adaptation). Oil and gas companies operate in complex natural and social environments, but for the sake of delimitations, in this article we discuss adaptations to unplanned internal changes in the form of departure of nodes in networks of interaction due to retirement.

\section{Mass Retirement from a System Resilience Approach}

According to Gao, Barzel and Barabási [23], resilience is one of the fundamental properties of complex systems. Folke [24] locates the origins of the concept of resilience in the study of ecology and discovery of multiple points of equilibria in ecosystems in the 1960s. This opened up the interest in the applications and implications of the concept of resilience for other kinds of systems. Both resilience and robustness relate to the capacity to respond to internal and external perturbations but resilience implies an adaptive capacity: 
"It is also about the opportunities that disturbance opens up in terms of recombination of evolved structures and processes, renewal of the system, and emergence of new trajectories. In this sense, resilience provides adaptive capacity that allows for continuing development, like a dynamic adaptive interplay between sustaining with change" [23] (p. 259).

For Barabási [19] (p. 330), a resilient system "can adapt to internal and external errors by changing its mode of operation without losing its ability to function. Hence, resilience is a dynamical property that requires a shift in the system's core activities". The concept has influenced different areas of knowledge and permeated attempts to model both natural and social complex systems. In studies of resilience, diversity is seen as decisive both for the capacity of absorbing disturbance and for the ability of re-organizing following perturbation [24]. According to Majdandizic, Pobonik, Buldyrev, Kenett, Havlin, and Stanley, although much research has been carried out on failure propagation due to unexpected events, different complex systems exhibit spontaneous recovery properties dynamics: "in many real-life phenomena such as brain seizures in neuroscience or sudden market crashes in finance, after an inactive period of time a significant part of the network becomes active again" [25] (p. 34). We may have to look at examples from other social systems to learn about network resilience. The work by Hobbs and Burke [26] is an important step in this direction. They compared how 15,000 Facebook networks behaved in response to the death of a friend. They observed that although some social interaction was initially lost, in most cases remaining, common friends of the deceased user tended to increase interactions with each other and maintain ties for years. They empirically observed network resilience in such groups. Their research on systems of human interactions have demonstrated that networks respond in different manners to crisis situations such as the departure of important agents: forming new temporary connections that dissolve over time, developing new longer-term connections, or; dissolving and possibly becoming dysfunctional [26].

We have so far limited knowledge on how such processes take place in human networks. As pointed out by Hobbs and Burke [26], there is little empirical foundation for models of resilience in systems of human organization. However, lessons about network resilience from other living systems can permeate new practices in oil and gas.

The traditional and the network approaches to knowledge loss in oil and gas are illustrated in Table 1:

Table 1. The traditional and the network approach.

\begin{tabular}{ccc}
\hline & Traditional Approach & Network Approach \\
\hline Survival mechanisms & Robustness & Resilience \\
Time perspective & Continuation & Evolutionary \\
System capabilities & Stability & Adaptability \\
Knowledge dimension & Explicit, individual & Explicit and tacit, built in interaction processes \\
Management focus & Individuals in formal hierarchies & Individuals in informal, emergent structures \\
\hline
\end{tabular}

As highlighted earlier, social networks are not designed. The webs of interactions among different individuals do not exist a priori, but are the emergent outcome of evolutionary processes. From an evolutionary perspective, we do not design networks, but we can learn to influence them in positive ways. According to March [9], the different strategies, policies and management practices that we implement in organizations can be seen from an evolutionary perspective as attempts to engineer organizational history. There are three ways of engineering the evolutionary history of organizations: changing the possibilities for transmission, retention, and retrieval of organizational knowledge; changing the structure of interactions, and; managing the balance between exploiting existing knowledge and exploring new possibilities. Having that in mind, we can say that strategies that change design of an organization are forms of intervention in organizational history that can either facilitate or restrict interactions among different individuals and units of adaptation. However, it is possible to understand emerging processes of interactions beyond formal hierarchical structures in 
order to implement successful interventions. In this respect, March [9] highlights the importance of small, local, and contextual interventions.

\section{Social Network Analysis}

The study of social networks highlights a central assumption in social sciences: individuals are part of dense webs of social relations and interactions [27]. SNA aims at providing answers to questions that have been raised at least since Plato's time approaching the dynamics from which social order arises from interactions among individuals: "how autonomous individuals can combine to creat, enduring, functioning societies" [27] (p. 892). Network analysis derives from initial developments in structural investigations in the 1930s using the metaphors of the web of social life that permeated efforts to understand "interweaving" and "interlocking" social relations [12] (p. 1). The development of SNA has been followed by a relational perspective in the study of social processes assuming relationships between individuals and their structure as the main unit of analysis [28-31].

Janssen, Bodin, Anderies, Elmqvist, Ernstson, McAllister, Olsson, and Ryan [32] claim that the levels of connectivity and centrality are important metrics related to systems resilience. Connectivity relates to the density of the network and is calculated by dividing the number of connections by the maximum number of possible connections. In organizational settings, centrality is usually interpreted as an indicator of information flow. Systems of human organization are always free-scale, meaning that some individuals have more links and are thereby more structurally connected than other nodes. The trade-off here is that although highly centralized networks may facilitate coordination and control, they may also restrict variation and be vulnerable to the sudden absence of central nodes. At this point, it is important to recognize it is not possible to identify a linear relation between the different metrics of a network and systems resilience. However, they contribute to understand the initial conditions from which changes may emerge. When different nodes or connections disappear, a resilient system would have the characteristic of adapting by incorporating new nodes or developing new connections. Organizational design can either restrain or facilitate such processes.

Social network analysis can inform open innovation practices. As stated by Yon, Won, and Park [33], open innovation requires flow of technology and knowledge across formal organizational structures.

\section{Network Robustness and Resilience in Oil and Gas Production}

One may argue that focus on systems resilience and networks of interactions may be a promising track for most industries. However, we hereby present some particularities of oil and gas production processes. It is important to recognize the organizational complexity of oil production. Oil platform operators do not usually have visual contact with processes taking place in oil wells or pipes in upstream processes. Therefore, operators build mental models and representations of such processes informed by formal indicators (temperature, pressure, output) and informal indicators (vibrations, noises, and sometimes other sensorial information due to physical proximity). Throughout their careers, operators develop tacit and experiential knowledge in the form of mental models necessary to perform operational tasks in an efficient and safe manner. This learning process takes place in a context of interdependence and information flow with other individuals. This knowledge dimension of oil and gas production has been described by an ethnographic fieldwork study in the industry [34]. The study focused on the everyday practice of production engineers who planned, optimized, and monitored oil production. Furthermore, an integral part of the daily work was to interact with other professional communities in the same company.

The recent history of accidents, such as Deep Horizon and Texas City Refinery, highlights risks in the oil and gas industry. The common industrial response to perceptions of risks of environmental and labor accidents has been an increasing standardization of work processes. These are policies aiming at limiting variation and interaction. The main focus here is on system robustness and exploitation of explicit knowledge. There are paradoxically other processes demanding a resilience approach and 
exploration. Another important external condition is the increasing social pressure for oil and gas companies to expand their portfolio towards renewable sources to become energy companies [35]. This is a major organizational challenge that will require increasing learning and adaptation.

Oil and gas production is in a complex interplay between exploitation, restricting variation and interaction, and exploration, which allow variation and webs of interaction. This has been empirically observed by a fieldwork study of the everyday life and interactions among oil platform operators in a major oil and gas company [36]. This study described how even in highly standardized work environments, it is possible to observe local adaptation processes in which operators explore new possibilities and create new knowledge. In practice, the two processes coexist organically rather than being separated in time and space.

From an evolutionary perspective, the knowledge management challenge of a retiring workforce raises questions about our possibilities of engineering organizational history in the light of complex adaptive processes. However, oil companies share important characteristics that place a focus on complex systems and an industry recognition of adaptive processes rather difficult to be accepted by most practitioners. Recognizing emerging and rather invisible webs of interaction can be culturally challenging in the oil and gas industry. Oil and gas companies have historically consolidated themselves as professional bureaucracies [37] in which skilled professionals perform their activities in a highly autonomous manner. In such bureaucratic structures, there is a concern with standardization of processes that from an evolutionary perspective can be seen as an attempt to restrict unwanted variation. As pointed out by Sandaker [10], designing organizations with the goal of standardizing process and products usually implies in restricting interaction to chains of command. On the other hand, the shift towards matching the complexity and competence of the environment involves allowing webs of influence by facilitating variation in interaction across individuals and organizational units [10]. Recognizing and understanding the behavior of webs of influence may contribute to the resilience system by facilitating the emergence of new connections and channels of information flow in response to crises generated by absence of certain nodes. The first one has an anticipatory logic, whereas the second has an adaptive logic.

\section{Network Analysis: Implications for Resilience and Practice in Oil and Gas}

Densely connected networks are more likely to present a redundancy of links making the system more robust and resilient to the departure of agents. However, this general assumption related to both artificial [38] and socio-ecological systems [24] has important nuances and implications to the study of resilience in systems of human organizations. It can inform practices in oil and gas in at least two ways: anticipating knowledge-loss risks and enabling resilience by engineering the network structure.

\subsection{Anticipatory: Maintaining Path Lengths and Preserving Information Flow}

Organizations can anticipate possible scenarios by understanding the structural position of individuals in the network. Parise, Cross, and Davenport [1] associate knowledge-loss risks with different network roles performed by individuals: central connectors, brokers and peripherals. Their identification of three network roles is based upon organizational network analysis in eighty companies in different sectors. The roles were identified through a combination of network structural analysis and interviews focusing on knowledge-loss risks associated with each role. Central connectors are highly connected individuals who may possess technical expertise, organizational memory, and experiential knowledge. The knowledge-loss risks may be reduced by increasing network redundancy and reallocating information access. Brokers are nodes who have ties among subgroups. They play a role in integrating full networks and therefore have broad knowledge of how the organization operates. In such cases, knowledge-loss risks can be addressed by developing brokers by engaging individuals in transdisciplinary cooperation and rotating staff across geographic units, divisions, and expertise groups. 
We may need to look at other systems to empirically learn about network resilience. In ecological systems, networks of interactions usually demonstrate resilience by maintaining path lengths, thereby preserving information flow. For example, it has been observed that ant colonies usually respond to the loss of nodes by increasing connectivity. This is due to the capacity of remaining individuals to rapidly establish new social connections [39]. This learning deriving from research in ecological systems may permeate practices in systems of human organization. While it may be the case that such spontaneous adaptations take place in some socio-ecological systems, adaptation may need to be engineered in other systems of human organizations. In rather complex oil and gas production operations in which there is interdependence among different areas of expertise, network analysis can help to map knowledge in the organization and inform interventions aimed at creating new interactions. In this respect, an important organizational change in oil and gas has been the consolidation of new collaborative work forms in production processes called integrated operations. The concept of integration in oil and gas refers to the consolidation of shared workspaces where operations are controlled in a collaborative manner $[34,40]$. In most companies, integrated operations take place in onshore collaboration rooms where multidisciplinary teams make use of real-time data sharing and communication technology to control offshore oil production operations. Integration derives from an understanding of complexity in oil production surveillance, thereby shifting from a previously dominant assumption that production processes could be understood and modelled distinctively from other processes [41]. Instead of structuring production processes in a sequential manner, integrated operations facilitate interactions by introducing collaborative work processes [42]. The implementation of integrated operations is a way of engineering the evolutionary history of such companies, by enabling new forms of interactions and facilitating cooperation and local processes of adaptation from which new knowledge may emerge [36]. It can contribute to the creation of redundancy in information flow and facilitate new interactions in the context of interdependence. Organizational network analysis can inform the design of integrated operation settings beyond formal structures.

\subsection{Enabling Network Resilience in Oil and Gas: The Importance of Network Silos and Bridges}

The knowledge possessed by leaving staff has often a highly tacit and experiential character that cannot be codified and stored. Loss of such forms of knowledge may be inevitable. Resilience in oil and gas will therefore require less dependence on previous knowledge by developing new network structures that facilitate the emergence and spread of new knowledge and innovative practices beyond formal hierarchical structures. The shift towards energy companies focusing on renewable sources will demand the creation of new knowledge and thereby open innovation systems. As described by Han [43] (p. 2), open innovation is always a "quest in the unknown".

In evolutionary processes, it is important to look at what happens with knowledge that is regarded as obsolete. One may inquire who or what determines which knowledge needs to be kept or which knowledge should be discarded. In this respect, Grubler and Nemet [44] claim that knowledge depreciation is usually related to two main variables: the degree of innovation-driven technological obsolescence and turnover of holders of that knowledge. The second variable is particularly related to the case of mass retirement in oil and gas. As the authors observe, high rates of staff turnover seem to be linked to knowledge depreciation. This is particularly the case in environments where knowledge remains largely tacit: knowledge deriving from experience rather than formal research seems to be more susceptible to depreciation and regarded as obsolete [44]. The authors argue that knowledge management may play an important role in minimizing volatility-driven depreciation by facilitating knowledge and technology cooperation networks. This is a claim that resonates with the network perspective that we develop in this article. Furthermore, from an evolutionary perspective, knowledge is either discharged or selected in the context of adaptation processes. Such processes can never be fully centrally designed but can be facilitated and influenced by management interventions.

As shown by Centola [16], while a densely connected network favors the spread of simple information, the diffusion of complex information in the form of change in norms and behaviors is 
highly related to mechanisms of social reinforcement in the context of local processes of interaction. The study consisted of network model simulations of interaction and information flows. His findings indicate that adaptive organizations tend to have a balanced network structure, with silos from which innovative ideas may emerge, but also wide bridges facilitating the spread of complex information: "while individuals may come and go, these enduring pathways can establish norms of social contagion across groups that sustain an organization's capacity for change" [16] (p. 133). Bearing that in mind, a promising track for promoting resilience in oil and gas companies may not lie in quantitatively increasing the number of connections-in environments which are often already overloaded with information - but rather to recognize the local processes of adaptation and open processes of communication across network silos. The silos are clusters that may not necessarily correspond to the formal organizational units. These are spaces where local interventions, sometimes in the form of informal interactions facilitated by middle managers, can play an important role.

Oil production and platform design are examples of activities that require communication across different areas of expertise. Platform design involves disciplines such as electrical engineering, naval architecture, ergonomic studies, structure, automation, safety systems, HSE (Health Safety and Environment, HVAC (Heating, Ventilation, and Air Conditioning), telecommunications and piping systems. Some individuals in each of these disciplines are formally appointed as focal points responsible for communicating with other areas. However, much of the multidisciplinary communication goes through informal channels of interaction, which may sometimes lead to the formation of clusters. The network structure of informal and rather emergent patterns of interaction can give indications of network resilience. This can inform practices that recognize the importance of clusters as spaces of social reinforcement, from which new knowledge can emerge and facilitate the consolidation of network bridges, through which innovative ideas can spread. The logic of integration that has permeated oil and gas production may be in itself a step in this direction. We need further research on the role of integrated operations in facilitating communication among organizational clusters.

\section{Conclusions}

From an evolutionary perspective, our attempts to design organizations can be seen as attempts to alter the evolutionary history of our companies by either constraining or enabling interaction and variation. In this respect, network analysis may not fully explain resilience. However, knowledge of network structure can help oil and gas companies to tackle the challenges of an aging workforce in at least two ways: first, by anticipating possible knowledge-loss risks by understanding the roles of retiring individuals in their network structure, which provides valuable information about the initial state of the system, anticipating possible scenarios; and second, by promoting network structure resilience, by understanding local processes of adaptation, but also bridges through which complex information in the form of ideas, norms, and social cooperation may spread. Furthermore, promoting system resilience in the oil and gas sector in the light of the departure of experienced new personnel will be highly related to how companies facilitate communication, information flow, and the exploration of new knowledge.

Author Contributions: F.B. and L.G. contributed equally in all stages for the development of this conceptual paper.

Funding: This research received no external funding.

Conflicts of Interest: The authors declare that they have no competing interests. 


\section{References}

1. Parise, S.; Cross, R.; Davenport, T. Strategies for preventing a knowledge-loss crisis. MIT Sloan Manag. Rev. 2006, 47, 31-38.

2. Sumbal, M.; Tsui, E.; Lee, W. Baby Boomers Retirement in Oil and Gas. In Proceedings of the 7th International Joint Conference on Knowledge Discovery, Knowledge Engineering and Knowledge Management, Lisbon, Portugal, 12-14 November 2015.

3. Yu, H.-C.; Miller, P. Leadership style: The X Generation and Baby Boomers compared in different cultural contexts. Leadersh. Organ. Dev. J. 2005, 26, 35-50. [CrossRef]

4. Addison, V. Workforce Challenges Remain for Oil, Gas Sector. Available online: http:/ /www.epmag.com/ workforce-challenges-remain-oil-gas-sector-788716\#p=full (accessed on 6 February 2019).

5. KPMG Global Energy Institute. When One Crisis Meets Another: Focusing on Talent for the Long Term. 2015. Available online: https://home.kpmg.com/xx/en/home/insights/2015/04/when-one-crisis-meetsanother-focusing-talent-long-term.html (accessed on 6 February 2019).

6. SHRM-Society for Human Resource Management. Preparing for an Aging Workforce Oil, Gas and Mining Industry Report. 2016. Available online: https:/ /www.shrm.org/hr-today/trends-and-forecasting/ research-and-surveys/Documents / Preparing_for_an_Aging_Workforce-Oil_Gas_and_Mining_Industry_ Report.pdf (accessed on 6 February 2019).

7. DeLong, D.W. Lost Knowledge: Confronting the Threat of an Aging Workforce, 1st ed.; Oxford University Press: Oxford, UK, 2004.

8. Byrne, D.; Callaghan, G. Complexity Theory and the Social Sciences. The State of the Art; Routledge: London, UK, 2014.

9. March, J. The evolution of evolution. In Evolutionary Dynamics of Organizations, 1st ed.; Baum, J., Singh, J., Eds.; Oxford University Press: Oxford, UK, 1994; pp. 39-49.

10. Sandaker, I. A selectionist perspective on systemic and behavioral change in organizations. J. Organ. Behav. Manag. 2009, 20, 276-293. [CrossRef]

11. Cross, R.; Parker, A.; Sasson, L. Introduction. In Networks in the Knowledge Economy; Cross, R., Parker, A., Sasson, L., Eds.; Oxford University Press: Oxford, UK, 2003; pp. 3-10.

12. Scott, J. Social Network Analysis, 3rd ed.; Sage: London, UK, 2013.

13. Cross, R.; Parker, A. The Hidden Power of Social Networks: Understanding How Work Really Gets Done in Organizations, 1st ed.; Harvard Business Review Press: Boston, MA, USA, 2004.

14. Clement, J.; Puranam, P. Searching for structure: Formal organization design as a guide to network evolution. Manag. Sci. 2017, 64, 3879-3895. [CrossRef]

15. Parise, S. Knowledge management and human resource development: An application in social network analysis methods. Adv. Dev. Human Res. 2007, 9, 359-383. [CrossRef]

16. Centola, D. How Behavior Spreads: The Science of Complex Contagions, 1st ed.; Princeton University Press: Princeton, NJ, USA, 2018.

17. Grant, R.M. The Development of Knowledge Management in the Oil and Gas Industry/El desarrollo de la Dirección del Conocimiento en la industria del petroleo y gas. Universia Bus. Rev. 2013, 40, 92-125.

18. Lam, A. Tacit knowledge, organizational learning and societal institutions: An integrated framework. Organ. Stud. 2000, 21, 487-513. [CrossRef]

19. Barabasi, A.L. Network Science, 1st ed.; Cambridge University Press: Cambridge, UK, 2016.

20. Anderies, J.; Folke, C.; Walker, B.; Ostrom, E. Aligning key concepts for global change policy: Robustness, resilience, and sustainability. Ecol. Soc. 2013, 18, 8-25. [CrossRef]

21. Nelson, R.; Winter, S. An Evolutionary Theory of Economic Change; Belknap Press of Harvard University Press: Cambridge, MA, USA, 1982.

22. March, J. Exploration and exploitation in organizational learning. Organ. Sci. 1991, 2, 71-87. [CrossRef]

23. Gao, J.; Barzel, B.; Barabási, L. Universal resilience patterns in complex networks. Nature 2016, 530, 307-312. [CrossRef] [PubMed]

24. Folke, C. Resilience: The emergence of a perspective for social-Ecological systems analyses. Glob. Environ. Chang. 2006, 16, 253-267. [CrossRef]

25. Majdandzic, A.; Podobnik, B.; Buldyrev, S.; Kenett, D.; Havlin, S.; Stanley, H. Spontaneous recovery in dynamical networks. Nat. Phys. 2014, 10, 34-38. [CrossRef] 
26. Hobbs, W.; Burke, M. Connective recovery in social networks after the death of a friend. Nat. Hum. Behav. 2017, 1, 1-6. [CrossRef]

27. Borgatti, S.; Mehra, A.; Brass, D.; Labianca, G. Network analysis in the social sciences. Science 2009, 323, 892-895. [CrossRef] [PubMed]

28. Crossley, N. Towards Relational Sociology, 1st ed.; Routledge: New York, NY, USA, 2010.

29. Martino, F.; Spoto, A. Social network analysis: A brief theoretical review and further perspectives in the study of information technology. PsychNology J. 2006, 4, 53-86.

30. Scott, J. Social network analysis: Developments, advances, and prospects. SNAM 2011, 1, 21-26. [CrossRef]

31. Zweg, K. Network Analysis Literacy: A Practical Approach to the Analysis of Networks; Springer: Vienna, Austria, 2016.

32. Janssen, M.; Bodin, Ö.; Anderies, J.; Elmqvist, T.; Ernstson, H.; McAllister, R.; Olsson, P.; Ryan, P. Toward a network perspective of the study of resilience in social-ecological systems. Ecol. Soc. 2006, 11, 15. [CrossRef]

33. Yun, J.J.; Won, D.; Park, K. Dynamics from open innovation to evolutionary change. J. Open Innov. Technol. Mark. Complex. 2016, 2, 1-22. [CrossRef]

34. Østerlie, T.; Almklov, P.; Hepsø, V. Dual materiality and knowing in petroleum production. Inf. Organ. 2012, 22, 85-105. [CrossRef]

35. Zhong, M.; Bazilian, M. Contours of the energy transition: Investment by international oil and gas companies in renewable energy. Electr. J. 2018, 31, 82-91. [CrossRef]

36. Bento, F. Complexity in the oil and gas industry: A study into exploration and exploitation in integrated operations. J. Open Innov. Technol. Mark. Complex. 2018, 4, 1-17. [CrossRef]

37. Bremda, B.; Korsvold, T. Knowledge markets and collective learning. Designing hybrid arenas for learning oriented collaboration. In Integrated Operations in the Oil and Gas Industry: Sustainability and Capability Development, 1st ed.; Rosendahl, T., Hepsø, V., Eds.; IGI Global: Hershey, PA, USA, 2013; pp. 304-327.

38. Albert, R.; Jeong, H.; Barabási, A.L. Error and attack tolerance of complex networks. Nature 2000, 406, 378-382. [CrossRef] [PubMed]

39. Naug, D. Structure and resilience of the social network in an insect colony as a function of colony size. Behav. Ecol. Soc. 2009, 63, 1023-1028. [CrossRef]

40. Henderson, J.; Hepsø, V.; Mydland, Ø. What is capability approach to integrated operations? An introduction to key concepts. In Integrated Operations in the Oil and Gas Industry: Sustainability and Capability Development, 1st ed.; Rosendahl, T., Hepsø, V., Eds.; IGI Global: Hershey, PA, USA, 2013; pp. 1-20.

41. Lochman, M. The future of surveillance: A survey of proven business practices for use in oil and gas. SPE Econ. Manag. 2012, 4, 235-247. [CrossRef]

42. OLF-Norwegian Oil Industry Association. Integrated Work Processes: Future Processes on the Norwegian Continental Shelf. 2005. Available online: https:/ /www.norskoljeoggass.no/PageFiles/14295/051101\% 20Integrerte\%20arbeidsprosesser,\%20rapport.pdf?epslanguage=no (accessed on 6 February 2019).

43. Han, J. Exploitation of architectural knowledge and innovation. J. Open Innov. Technol. Mark. Complex. 2017, 3, 1-15. [CrossRef]

44. Grubler, A.; Nemet, G. Sources and consequences of knowledge depreciation. In Historical Case Studies of Energy Technology Innovation, 1st ed.; Grubler, A., Wilson, C., Eds.; Cambridge University Press: Cambridge, UK, 2014; pp. 133-145.

(C) 2019 by the authors. Licensee MDPI, Basel, Switzerland. This article is an open access article distributed under the terms and conditions of the Creative Commons Attribution (CC BY) license (http://creativecommons.org/licenses/by/4.0/). 